\title{
Um experimento sobre a interpretação de metáforas: investigando o papel dos esquemas imagéticos, da semântica e do contexto
}

\section{An experiment on the interpretation of metaphors: investigating the role of image schemes, semantics and context}

Viviane Folden

University of South Florida, Tampa (USF), Flórida, Estados Unidos.

viviane.vilar@uol.com.br

Heronides Moura

Universidade Federal de Santa Catarina (UFSC), Florianópolis, Santa Catarina, Brasil. heronides@uol.com.br

Mailce Borges Mota

Universidade Federal de Santa Catarina (UFSC), Florianópolis, Santa Catarina, Brasil. mailcemota54@gmail.com

Gustavo Estivalet

Laboratoire sur le Langage, le Cerveau et la Cognition, Université de Lyon, França. gustavolopezestivalet@gmail.com

Resumo: Tendo como base os conceitos da semântica cognitiva, investigamos a contribuição relativa $(\mathrm{CR})$ de restrições imagéticas, contextuais e semânticas no processamento de metáforas. Participaram do estudo 53 indivíduos falantes de português brasileiro que foram solicitados a realizar tarefas de priming em três condições: uma condição de priming imagético, uma condição de priming contextual e uma condição de priming semântico. Juntos, os resultados da análise estatística mostram que os participantes foram sensíveis aos elementos linguísticos - semânticos e contextuais -, ao qual uma metáfora está conectada e que a restrição contextual é a que mais influencia a interpretação da metáfora, seguida da restrição semântica. 
Palavras-chave: semântica cognitiva, processamento metafórico, contexto, esquema imagético.

\begin{abstract}
Based on the constructs of cognitive semantics, we investigated the relative contribution of imagetic, contextual, and semantic restrictions to the processing of metaphors. Fifty-three native speakers of Brazilian Portuguese participated in the study and were required to perform priming tasks under three conditions: an imagetic priming condition, a contextual priming condition, and a semantic priming condition. Together, the results of the statistical analysis show that participants were sensitive to the linguistic elements - semantic and contextual -, to which a metaphor is connected, and that the processing of metaphors is heavily influenced by contextual restrictions first, then followed by semantic restrictions.
\end{abstract}

Keywords: cognitive semantics, metaphoric processing, context, image scheme.

Recebido em: 28 de setembro de 2014. Aprovado em: 9 de junho de 2015.

\title{
1 Introdução
}

Esta pesquisa visa determinar o papel representado por três tipos de restrições que interferem no processamento de metáforas: restrições imagéticas, restrições contextuais e restrições semânticas. Embora hajam muitos estudos indicando que essas três variáveis são importantes para a interpretação de uma metáfora (KITTAY; LEHRER, 1981; LAKOFF; JOHNSON, 1980 [2002]; LAKOFF, 1987; GLUCKSBERG; KEYSAR, 1990; GIBBS, 1994; MCGLONE, 1996; LAKOFF; JOHNSON, 1999; LEEZENBERG, 2001; MOURA, 2006, 2007; PINKER, 2008), ainda não fica claro qual é a força relativa de cada uma dessas restrições no processamento da metáfora.

O objetivo desta pesquisa foi investigar o papel de restrições imagéticas, semânticas e contextuais no processamento de instâncias metafóricas analisadas por meio de estudo experimental. Pretendeu-se 
responder às seguintes perguntas: a) qual é a contribuição relativa (CR) de cada uma das restrições?; e b) houve diferença significativa no resultado das tarefas no que diz respeito à $\mathrm{CR}$ das restrições para a ativação de determinada interpretação de uma metáfora?

A hipótese deste trabalho é a de que o processamento (interpretação) de uma instância metafórica é determinado por restrições lexicais (restrições impostas pelo priming semântico dos elementos que ocorrem na posição de veículo dessas metáforas), restrições imagéticas (restrições impostas pelos esquemas imagéticos associados aos veículos das metáforas) e restrições contextuais (restrições impostas pelo contexto discursivo em que se situa a metáfora).

Esta pesquisa teve por base conceitos e perspectivas da semântica cognitiva. O significado da metáfora foi visto como resultado de um processo de construção, com base em restrições semânticas, imagéticas e contextuais. Assumimos, assim, a definição de Croft e Cruse (2009, p. 194): ${ }^{1}$

Os linguistas cognitivistas rejeitam a chamada teoria da substituição da metáfora, segundo a qual a expressão metafórica substitui alguma expressão literal. Isso tem o mesmo significado. Metáforas 'verdadeiras', em geral, não são literalmente parafraseáveis: elas têm algo que não tem expressão literal. [...] O significado metafórico não é, pelo menos em seus aspectos funcionais básicos, um tipo especial de significado: é antes um processo de construção para se chegar a, ou interpretar, um significado.

Supomos, assim, que o processo de interpretação de metáforas envolve um percurso cognitivo regido por essas três restrições:

\footnotetext{
${ }^{1}$ Original: "Cognitive linguists reject the so-called substitution theory of metaphor, according to which a metaphorical expression replaces some literal expression. That has the same meaning. Metaphors ('true' metaphors), in general, are not literally paraphrasable: they have a character that no literal expression has. [...] Metaphorical meaning is not, at least in basic functional respects, a special kind of meaning: it is rather the case that metaphor is the result of a special process for arriving at, or construing, a meaning." (CROFT; CRUSE, 2009, p. 194).
} 
imagéticas, semânticas e contextuais. Ou seja, o processamento da metáfora é visto como aberto e variável, mas não livre de qualquer condicionamento. As restrições apontadas funcionam como input para o processo de interpretação.

A base de dados de metáforas foi constituída de metáforas sobre emoções, em língua portuguesa, coletadas nos exemplares de uma revista feminina de circulação nacional: "Marie Claire". Essa escolha se deu devido ao fato de que, por se tratarem de depoimentos reais sobre a vida cotidiana e por esses depoimentos serem imbuídos de emoção, a linguagem empregada nesses depoimentos é carregada dessas metáforas. Assim, uma vez que, de certa forma, a "emoção" e o sentimento passam a ser protagonistas desses discursos, tanto por parte dos falantes que enunciam essas metáforas quanto por parte dos leitores que as interpretarão, percebeu-se, então, um repertório de dados farto e produtivo para a construção dessa base de dados para a presente pesquisa.

Há uma relação muito forte entre emoção e metáfora. Kövecses (2004, p. 20) defende que "a metáfora é bastante presente não apenas na linguagem que as pessoas usam quando falam de emoções, mas também que ela é essencial para a compreensão de boa parte dos aspectos da conceptualização da emoção e da experiência emocional"². A linguagem figurativa é também um instrumento de reconstrução do "self" na situação interacional, permitindo uma reelaboração conceitual de experiências pessoais marcantes e mesmo traumáticas (KUPFERBERG, 2007).

A coleta das metáforas foi realizada no período de maio de 2010 a setembro de 2012. Foram analisados textos de depoimentos de leitoras e leitores da "Marie Claire", de volumes de 2009 a 2012, que escrevem à revista porque querem ter suas histórias de vida publicadas. Desses textos, foram retiradas as instâncias metafóricas analisadas nesta pesquisa.

A parte experimental desta pesquisa foi constituída de um experimento composto por três tarefas interligadas e contrabalanceadas

\footnotetext{
2 Original: “[...] metaphor not only pervades the language people use about the emotions, but also that it is essential to the understanding of most aspects of the conceptualization of emotion and emotional experience".
} 
entre si. A metodologia experimental e de análise dos resultados deste experimento será apresentada na próxima seção.

A metodologia de análise de dados derivados da aplicação das tarefas com os participantes constou de análises estatísticas para se avaliar qual a CR de cada restrição e se houve a prevalência de uma sobre outra. No presente estudo, foram utilizados os testes estatísticos Teste-T de Student e Anáises de Variância (ANOVA). Em todos os testes, o valor do alpha foi estabelecido em 0.05 . Com isso, pretendeu-se verificar se as restrições propostas neste trabalho podiam ser ranqueadas hierarquicamente.

Antes de sua realização, este estudo foi submetido e aprovado pelo Comitê de Ética em Pesquisa da Universidade Federal de Santa Catarina (UFSC), de número 31.681, e como parte da metodologia desenvolvida para esta pesquisa, foi realizado um estudo piloto, a fim de se testarem os instrumentos que seriam utilizados.

\section{Experimento}

Para os objetivos deste trabalho, foi realizado um experimento composto por três tarefas interligadas. As três tarefas foram as seguintes: 1) tarefa de restrição imagética; 2) tarefa de restrição semântica; e 3) tarefa de restrição contextual.

A tarefa de restrição imagética apresenta uma metáfora seguida de um esquema imagético (uma animação) como priming, a fim de motivar uma restrição não verbal na escolha da resposta que o participante deveria subsequentemente realizar.

A tarefa de restrição semântica apresenta uma metáfora seguida de uma palavra-chave como priming, a fim de motivar uma restrição semântica na escolha da resposta que o participante deveria realizar em seguida. A palavra escolhida como priming, nessa tarefa, mantém alguma conexão semântica com o veículo da metáfora a ser interpretada, por isso denominamos a tarefa como sendo de restrição semântica, embora ela seja estimulada pela apresentação de um item lexical. É possível que esse priming esteja associado à memória semântica evocada pelo veículo da metáfora. 
Finalmente, a tarefa de restrição contextual apresenta diretamente uma metáfora contextualizada como priming, a fim de motivar uma restrição contextual da metáfora na resposta que o participante deveria realizar posteriormente. O contexto, nesta tarefa, é constituído de um excerto de texto retirado da base de dados, contendo a metáfora a ser analisada.

Foram selecionados 42 participantes, sendo 21 do sexo feminino e 21 do sexo masculino, adultos, universitários - graduandos e pósgraduandos -, alguns dos quais já frequentaram ou estão frequentando mais de um curso universitário. O objetivo da escolha desse perfil foi obter participantes com acesso a vários meios de informação e leitura, para que eles possivelmente tivessem tido contato com uma diversidade de metáforas e de expressões idiomáticas correntes na língua portuguesa do Brasil. Para a pilotagem dos experimentos, foram considerados outros 11 participantes, perfazendo um total de 53 , todos voluntários.

Esses participantes foram contatados pessoalmente por meio de um convite informal para que comparecessem ao laboratório do Núcleo de Estudos em Semântica Lexical (NES), da UFSC. No laboratório do NES, os voluntários responderam a um questionário informativo e também leram e assinaram um Termo de Consentimento Livre e Esclarecido.

Para o experimento conduzido nesta pesquisa, foram utilizados os seguintes materiais: 1) as tarefas aplicadas tanto no experimento quanto no estudo piloto foram programadas no software específico para o desenvolvimento de tarefas psicológicas E-Prime v2.0 Professional ${ }^{3}$ (SCHNEIDER; ESCHMAN; ZUCCOLOTTO, 2007), desenvolvido pela Psychology Software Tools, Inc. (PSTNET); 2) as tarefas foram apresentadas aos participantes em um computador portátil de 14 polegadas Samsung RV420 e foram desenvolvidas para que os participantes a realizassem de forma absolutamente autônoma, apenas seguindo as instruções que apareceriam na tela.

Para tanto, desenvolveram-se 30 estímulos, sendo 21 instâncias metafóricas e nove distratores, formados a partir de instâncias metafóricas selecionados de textos de uma revista feminina de circulação nacional no

\footnotetext{
${ }^{3}$ Disponível em: <http://www.pstnet.com/eprime.cfm>. Acesso em: 28 jun. 2014.
} 
Brasil, "Marie Claire", da Editora Globo no período de maio de 2010 a setembro de 2012. Tendo em vista que o estudo é formado por três tarefas em diferentes modalidades de restrição metafórica (imagética, semântica e contextual), cada uma dessas instâncias metafóricas foi associada aos três tipos de priming, totalizando 90 possibilidades de estímulos. Assim, esses estímulos foram contrabalanceados e divididos em três listas de 30 estímulos (10 estímulos diferentes para cada tipo de priming), de forma que os participantes não vissem a mesma metáfora duas vezes.

Desses textos foram retiradas as instâncias metafóricas e expressões idiomáticas que seriam analisadas nesta pesquisa. Essas metáforas e expressões não foram inseridas nas tarefas tal qual apareciam nos textos originais das revistas. Como a estimulação foi $100 \%$ visual e de leitura, houve manipulação do número de sílabas dos estímulos, visando o controle do tempo de exposição desses estímulos em tela.

Analisaram-se 30 exemplos de sentenças, entre elas, 21 metáforas e nove expressões idiomáticas. Como critério metodológico de classificação dessas sentenças em metáforas (M) e expressões idiomáticas (E), foi decidido que seriam consideradas como expressões idiomáticas as sentenças que ocorrem com mais frequência na língua portuguesa do Brasil. Ou seja, optamos por um critério de uso, e não por um critério semântico.

Uma expressão idiomática é reconhecida, do ponto de vista do processamento, quando a sua configuração típica é facilmente identificada. Por esse aspecto, o processo de reconhecimento de uma expressão idiomática se assemelha ao reconhecimento de palavras, e não ao de frases. Por outro lado, no reconhecimento de uma expressão idiomática, ao contrário do que ocorre com palavras, não há ativação imediata de vários sentidos possíveis. A interpretação só é realizada quando a palavra-chave da expressão idiomática é ativada (GLUCKSBERG, 2001, p. 6). Assim, por exemplo, na expressão idiomática "João bateu as botas", o reconhecimento da expressão ocorre quando a palavra-chave "botas" é enunciada. Há uma configuração comum e reconhecível da expressão idiomática, ao passo que essa configuração não se faz presente em metáforas como "enterrei o desejo". Uma diferença plausível, portanto, entre expressão idiomática e metáfora 
é que há uma palavra-chave (do ponto de vista do processamento), no caso da expressão idiomática, ao passo que tal palavra favorecedora do reconhecimento não está presente no caso da metáfora.

O tempo de exibição das metáforas em estímulos foi ajustado, dependendo do número de sílabas (200 milissegundos para cada sílaba), para que as sentenças tivessem o mesmo nível de dificuldade. Os estímulos (metáforas e distratores) também foram manipulados para que não excedessem 2.000 milissegundos de exposição. Outra manipulação metodológica ocorreu com os estímulos para a escolha da interpretação por parte dos participantes. Como a média de tempo de exposição para esses estímulos seria superior a 5.000 milissegundos, devido ao número de sílabas totais das quatro opções de respostas, foi decidido que o tempo de exposição seria fixado em 5.000 milissegundos, para que o participante efetuasse sua escolha de interpretação e a tarefa continuasse.

De uma forma geral, os participantes deveriam primeiramente observar e ler a M ou E, observando o priming - animação quando imagético, item lexical quando restrição semântica, ou o contexto em que a metáfora foi produzida, quando contextual. A tarefa do participante era de escolher uma resposta entre quatro opções, apresentadas ao final de cada estímulo. Cada uma dessas respostas tinha uma relação com o veículo da metáfora e o estímulo apresentado, sendo assim: 1) resposta correta $(\mathrm{C}), 2$ ) resposta neutra $(\mathrm{N}), 3$ ) resposta antônima (A) e 4) resposta impossível (I). Destaca-se que esta ordem foi alterada de acordo com o quadrado latino, quando na programação das tarefas, para que os participantes não se acostumassem com o padrão de respostas.

Para todos os conjuntos de opções de interpretação $(1,2,3,4)$, havia: uma resposta correta; uma resposta também correta, mas neutra, isto é, que pudesse ser associada à interpretação da metáfora; uma resposta antônima; e uma resposta absolutamente impossível, ou distratora. Damos abaixo, no Quadro 1, um exemplo de metáfora usada nas tarefas, e as respostas oferecidas: 
Quadro 1 - Exemplo de metáfora e as respectivas respostas

\begin{tabular}{ll}
\hline \multicolumn{1}{c}{ Resposta } & \multicolumn{1}{c}{ Frase } \\
\hline \multicolumn{1}{c}{ Metáfora } & Enterrei esse desejo. \\
Resposta Correta (C) & Resisti à atração física. \\
Resposta Neutra (N) & Esqueci que desejava algo. \\
Resposta Antônima (A) & Mostrei o que sentia. \\
Resposta Impossível (I) & Perdi a fome. \\
\hline
\end{tabular}

Fonte: os autores.

A Figura 1 a seguir representa a sequência da Tarefa 1:

Figura 1 - Sequência de apresentação da Tarefa 1 (imagética) ${ }^{4}$

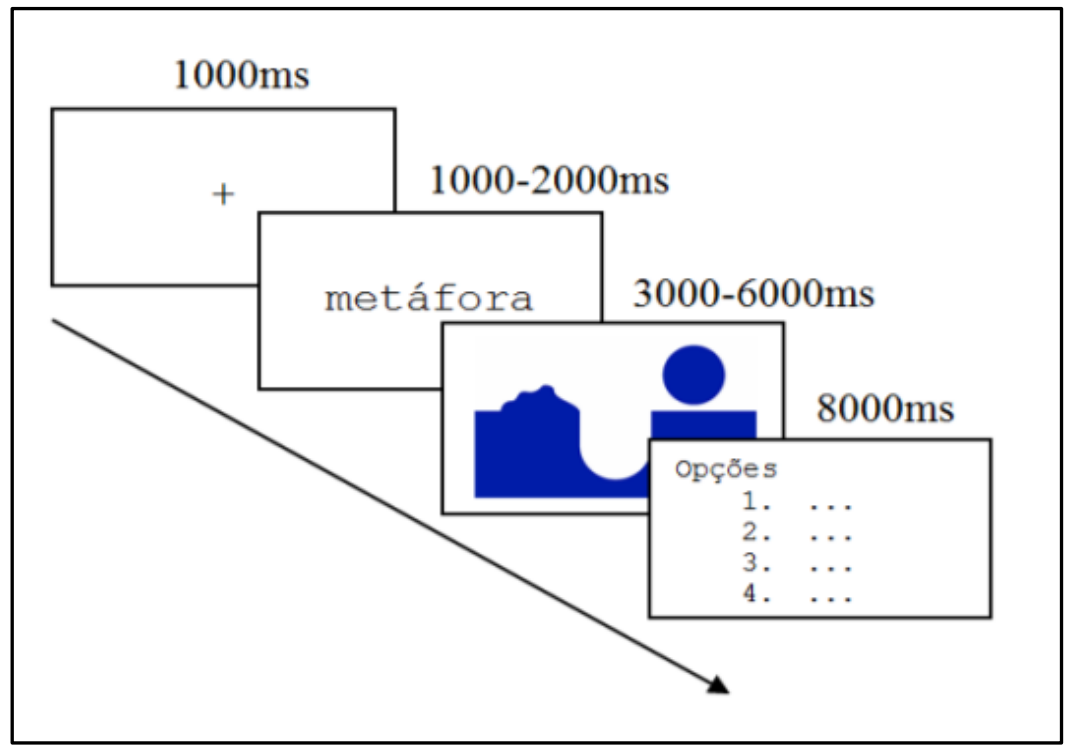

Fonte: os autores.

${ }^{4}$ Deve-se ter em mente que os esquemas imagéticos foram apresentados em forma de animação. Por exemplo, o desenho desta figura (para a metáfora "enterrei esse desejo") ilustra uma animação em que a bolinha à direita cai no buraco, e o monte de areia à esquerda recobre a bolinha. Era essa animação que o participante via. 
A Figura 2 a seguir ilustra a sequência da Tarefa 2.

Figura 2 - Sequência de apresentação da Tarefa 2 (lexical)

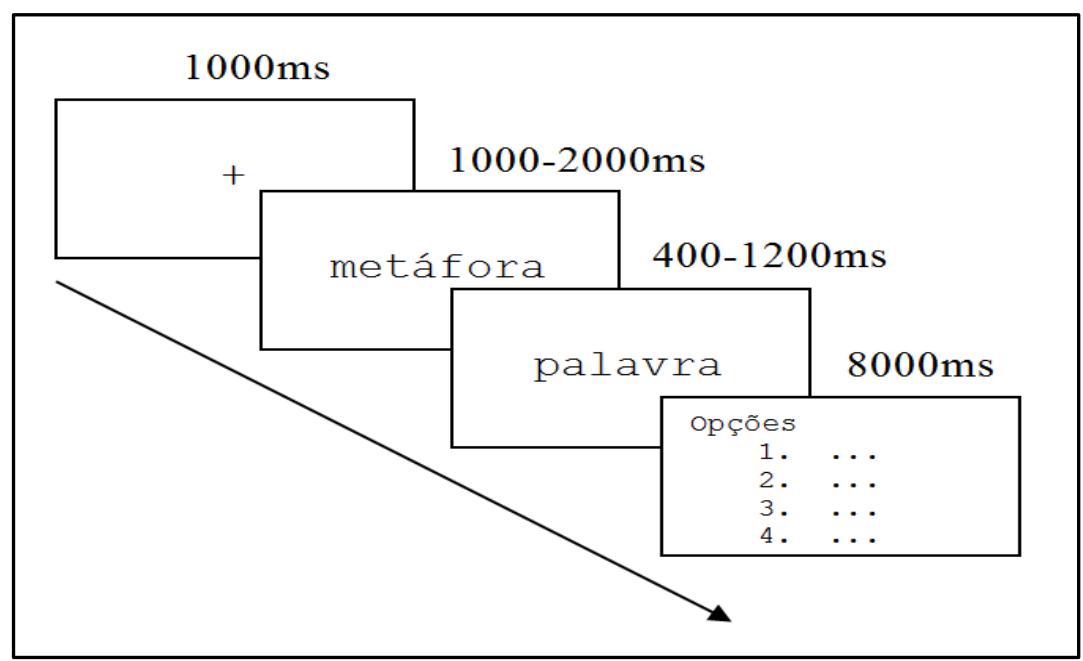

Fonte: os autores.

E a Figura 3 a seguir ilustra a sequência da Tarefa 3.

Figura 3 - Sequência de apresentação da Tarefa 3 (contextual)

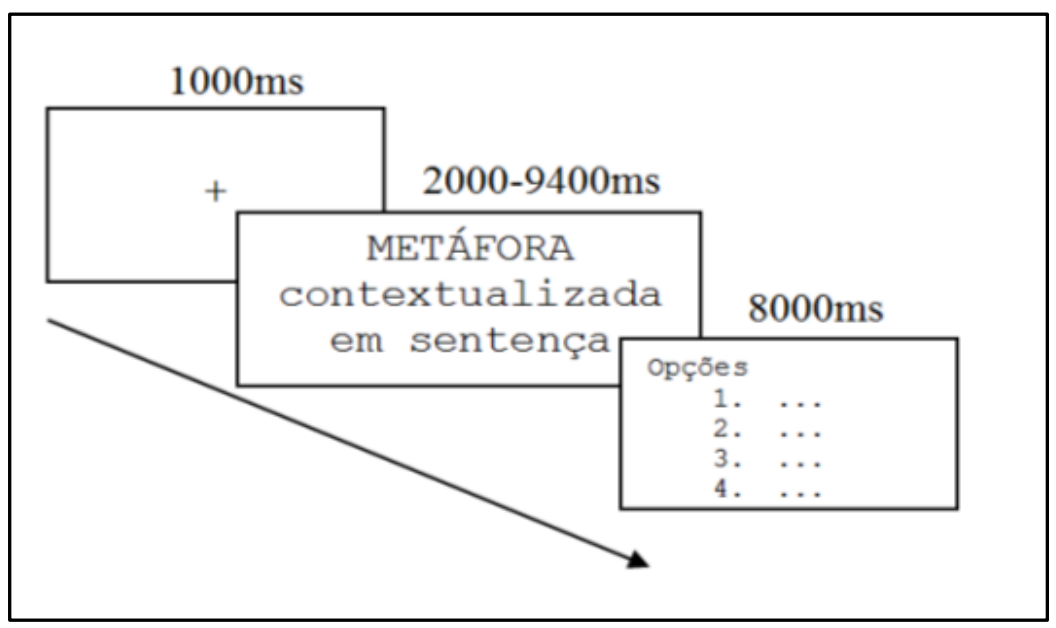


Fonte: os autores.

\section{Resultados e Discussão}

Nesta seção são descritos os resultados do estudo e, ao final de cada análise, esses resultados são discutidos. Após a análise da acurácia geral de respostas aos estímulos, da acurácia de respostas aos estímulos sem os distratores e da acurácia por priming ou tarefa, pode-se perceber um primeiro comportamento do tipo de restrição em relação à acurácia das respostas para cada tipo de priming. Observa-se que as respostas corretas representam 27,34\% das respostas totais. Mais do que isso, observa-se que os participantes tendem a errar mais as metáforas apresentadas com um priming imagético, já que essas são o tipo de metáforas que têm mais erros $(76,21 \%$ de erros), em relação ao priming semântico (70,21\%) e do priming contextual (71,56\%). Sendo assim, pode-se identificar uma diferença entre esquema imagético e informação linguística ou verbal. Consideramos que as restrições podem ser de dois tipos: não verbais (imagéticas) e verbais (semânticas e contextuais).

Após a retirada dos distratores, equivalente a 30\% do total das respostas, a proporção de acurácia continua praticamente a mesma, apresentando com um pequeno aumento $(27,94 \%)$, certamente devido a possibilidade de haver quatro respostas possíveis, deixando uma grande abertura para a escolha da interpretação, bem como a sensação de necessidade de uma escolha rápida por parte do participante.

Em seguida, foi feita a análise apenas sobre as respostas corretas para cada tipo de tarefa ou restrição, conforme a Tabela 1, e, ao final, foi feita uma análise de erro para melhor se compreender o comportamento geral dos dados obtidos.

Tabela 1 - Respostas corretas

\begin{tabular}{ccc}
\hline Priming & Número de acertos & Porcentagem de acertos \\
\hline Imagético & 65 & $24,62 \%$ \\
Semântico & 99 & $37,50 \%$ \\
Contextual & 100 & $37,88 \%$ \\
\hline
\end{tabular}

Fonte: os autores. 
Conforme dito anteriormente, fica claro que as respostas dos participantes em relação às metáforas apresentadas com priming linguístico (semântico e contextual) têm um resultado mais acurado de acertos em relação à escolha da interpretação, ao passo que as metáforas com priming imagético têm maior quantidade e proporção de erros.

$\mathrm{Na}$ distribuição da densidade dos acertos no Gráfico 1 para participantes, a seguir, percebeu-se que a maior parte deles obteve seis acertos das 21 metáforas. No gráfico de itens, Gráfico 2, observou-se que cada item teve em média 10 respostas corretas. A linha contínua sinaliza a média geral, e as linhas pontilhadas sinalizam a média geral mais e menos 2 desvios-padrão. A média de densidade de acerto dos participantes foi de 6,05 com desvio-padrão de 1,73; e a média de densidade de acerto dos itens foi de 12,38, com desvio-padrão de 7,32.

Gráfico 1 - Densidade de acertos dos participantes

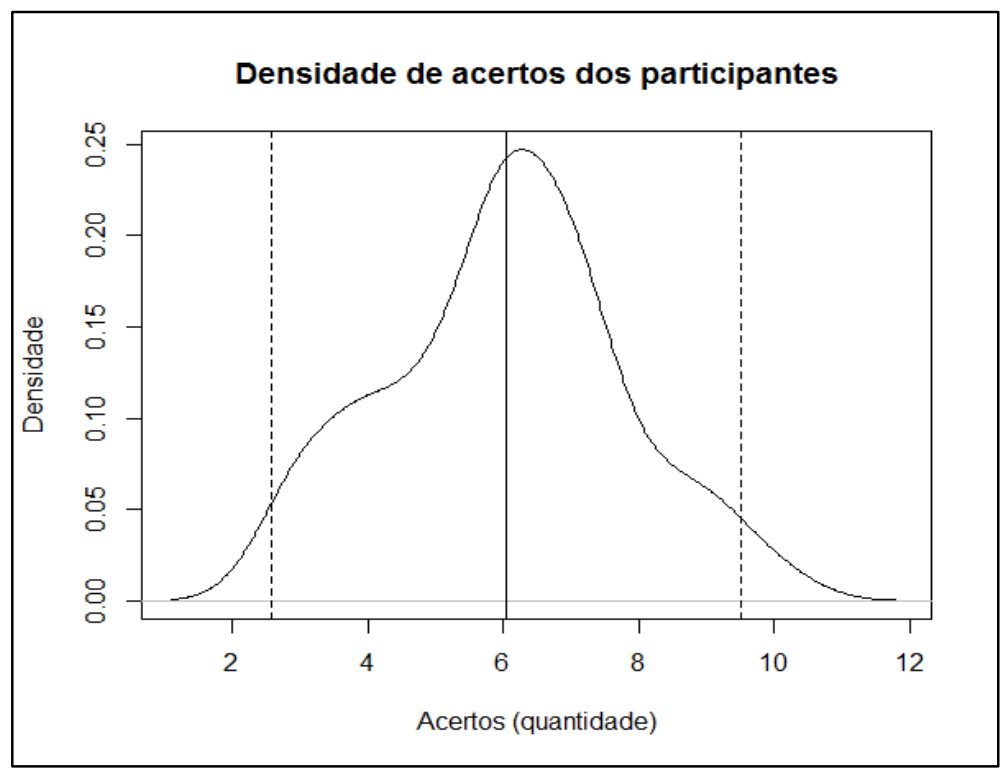

Fonte: os autores. 
Gráfico 2 - Densidade de acertos dos itens

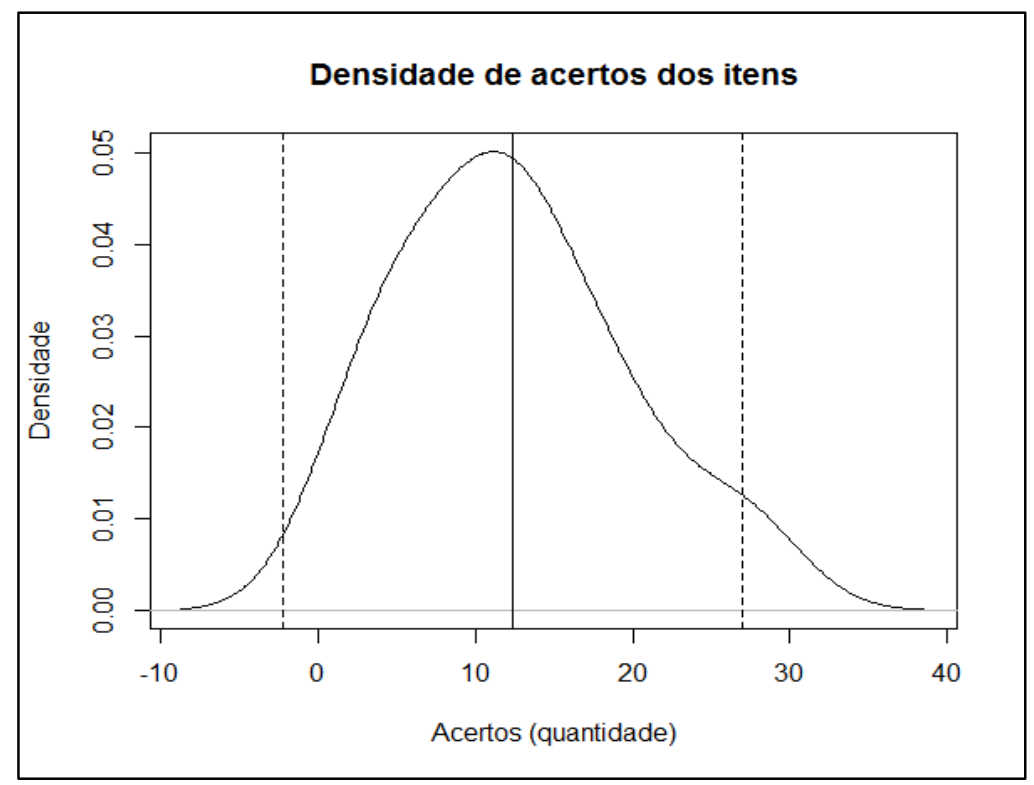

Fonte: os autores.

No Gráfico 3, os valores menores que 0 (zero) devem ser desconsiderados, pois a função de densidade utiliza uma distribuição normal e, tendo em vista o grande número de erros, ele acaba criando uma cauda à esquerda de 0 . No entanto, é interessante observar que, em relação às respostas dos participantes, as metáforas com o priming imagético têm uma distribuição de densidade diferente das metáforas com priming semântico e priming contextual. Estas últimas têm um comportamento bem semelhante. 
Gráfico 3 - Densidade de acertos dos participantes por tipo de restrição

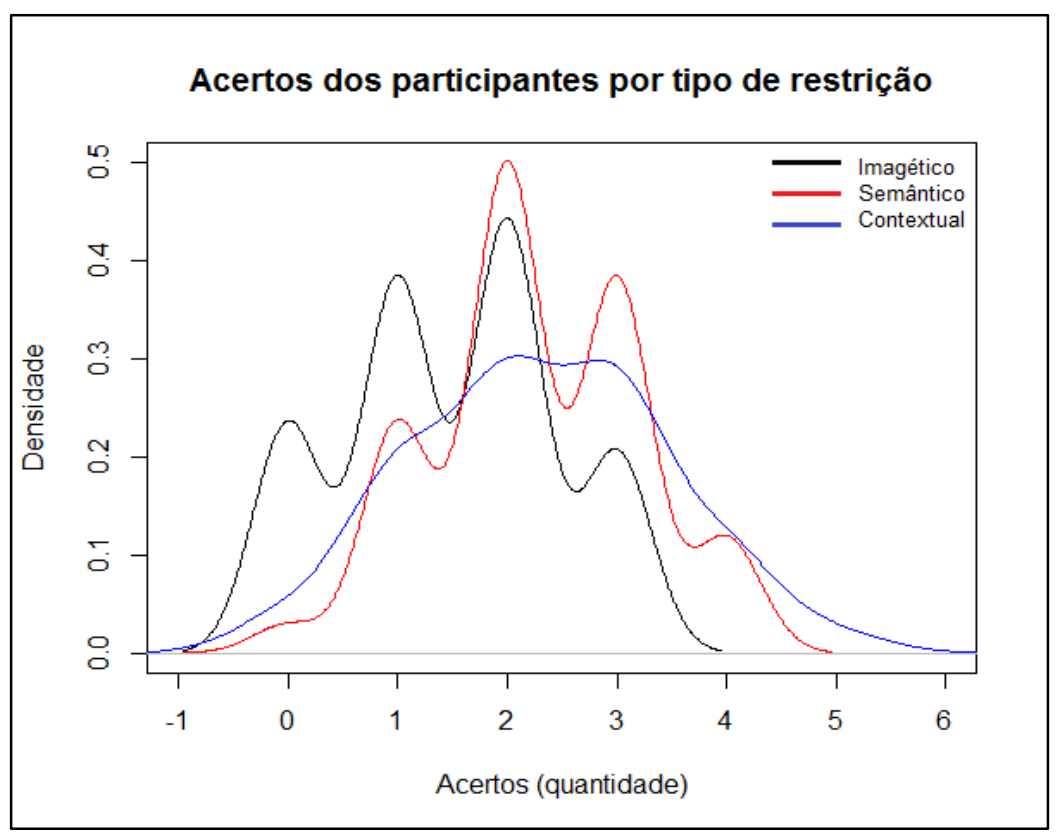

Fonte: os autores.

Igualmente, no Gráfico 4, os valores menores que 0 devem ser desconsiderados, pois a função de densidade utiliza uma distribuição normal e, tendo em vista o grande número de erros, ele acaba criando uma cauda à esquerda de 0 . Contudo, é interessante observar que, em relação às respostas dos itens, as metáforas com priming imagético têm uma distribuição de densidade com dois picos e, em seguida, uma queda brusca do número de respostas corretas, ao passo que as distribuições de metáforas com priming semântico e priming contextual têm uma descida à direita mais atenuada e, no caso do priming semântico, com dois picos pequenos em quatro e sete respostas corretas.

Logo, pode-se observar que os participantes parecem ter, de modo geral, o mesmo tipo de comportamento com primings linguísticos. Enfim, nesses dois gráficos, verifica-se que as metáforas com priming 
contextual têm distribuição mais regular e mais próxima da distribuição normal.

Gráfico 4 - Densidade de acertos dos itens por tipo de restrição

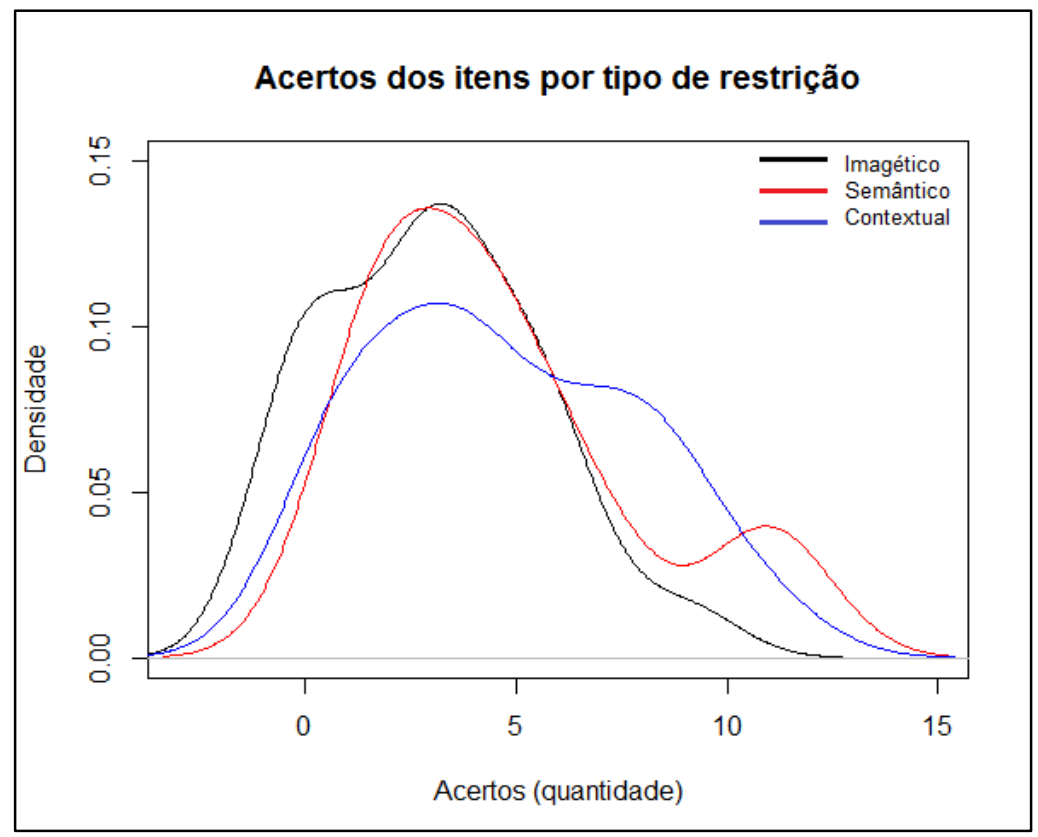

Fonte: os autores.

Dois grupos foram analisados por meio de ANOVAs: F1 participantes e F2 - itens: $F 1(2,126)=8,98, p<0,001$ e $F 2(2,60)=$ $2.06, p=0,081$. Esse resultado significativo mostra que há uma diferença em relação à taxa de acertos entre os tipos de priming.

De imediato, percebe-se que há uma diferença significativa entre priming imagético e contextual e entre priming semântico e imagético, mas não significativa entre semântico e contextual. Esse resultado vai perfeitamente ao encontro dos primeiros dados apresentados anteriormente.

Neste ponto, é interessante observar que se encontra efeito do tipo de priming para F1, "participantes", mas não se encontra nenhum efeito em relação ao tipo de priming para F2, "itens". Esses resultados podem ser interpretados como: para os participantes, o tipo de priming 
influencia na resposta a ser escolhida, ou seja, primings linguísticos (imagéticos e contextuais) permitem maior número de repostas corretas em relação ao priming imagético e essa diferença é estatisticamente significativa.

Para os "itens", independentemente do tipo de priming, não há uma diferença estatística significativa em relação ao número de acertos. Assim, podemos chegar à hipótese de que as metáforas não estão associadas a nenhum tipo de representação, nem imagética, nem semântica, nem contextual. Ou seja, a metáfora 1 (enterrei esse desejo), por exemplo, não é mais interpretável com priming imagético, nem semântico, nem contextual. Mas existe a necessidade de um estudo futuro, somente sobre as metáforas, para que se comprove essa hipótese, ou seja, para investigar se determinada ocorrência metafórica é mais facilmente interpretada em função do tipo de estímulo.

A fim de identificarem-se exatamente as diferenças significativas através de comparações planificadas, o mesmo tipo de análise empreendido anteriormente foi realizado com meio de Testes-T. Assim, há somente uma diferença estatística significativa entre priming imagético e priming semântico e entre priming imagético e priming contextual para $\mathrm{T} 1$, ou seja, para participantes, conforme a Tabela 2, a seguir.

No entanto, por meio dos Testes-T, pode-se verificar que as diferenças entre imagem e semântica e entre imagem e contexto são marginais: 0,086 e 0,067, respectivamente, o que apoia ainda mais a hipótese de que os priming linguísticos têm um comportamento diferente do priming imagético.

Tabela 2 - Testes-T

\begin{tabular}{ll}
\hline Comparação & Teste-T \\
\hline Imagético - Semântico & $\mathrm{T} 1(83)=3,67, \mathrm{p}<0,001 * *$ \\
& $\mathrm{~T} 2(38)=1,76, \mathrm{p}=0,086$ \\
Imagético - Contextual & $\mathrm{T} 1(82)=3,53, \mathrm{p}<0,001 * *$ \\
& $\mathrm{~T} 2(39)=1,88, \mathrm{p}=0,067$ \\
Semântico - Contextual & $\mathrm{T} 1(81)=0,20, \mathrm{p}=0,835$ \\
& $\mathrm{~T} 2(40)=0,09, \mathrm{p}=0,923$ \\
\hline
\end{tabular}


Fonte: os autores.

Antes de se realizar a análise de item, foi importante compreender o comportamento das respostas dos participantes de uma forma geral. Lembrando-se de que os participantes tinham quatro opções de resposta, obteve-se a seguinte distribuição das respostas: 369 $(27,34 \%)$ respostas correta $(\mathrm{C}), 652(48,30 \%)$ respostas neutras $(\mathrm{N}), 83$ $(6,15 \%)$ respostas antônimas $(\mathrm{A}), 111(8,21 \%)$ respostas impossíveis (I) e $135(10,00 \%)$ respostas nulas (NULL).

De acordo com o esperado, percebe-se que houve um número muito menor para as respostas A e I, assim como estímulos que não foram respondidos (NULL). O maior número de respostas se concentrou em $\mathrm{C}$ e N. Note-se que houve mais respostas para $\mathrm{N}$ do que para $\mathrm{C}$. Esses resultados podem ser interpretados como evidência para o fato de que, frente a alguma dificuldade para escolher as respostas, ou mesmo a por conta da formulação das opções, os participantes preferem escolher uma resposta mais "neutra" a se comprometerem com uma resposta mais restrita.

Outra explicação para esse resultado é que várias escolhas de opções de respostas $\mathrm{N}$ são respostas corretas também. Considera-se que a interpretação de uma metáfora, ainda que seja condicionada por restrições verbais e não verbais, não é um processo inteiramente determinístico, que conduz necessariamente a um único resultado.

Em seguida, comparando-se o número de respostas para cada tipo de resposta em relação aos diferentes tipos de priming, obtem-se a Tabela 3.

Tabela 3 - Respostas por tipo de restrição

\begin{tabular}{cccc}
\hline Resposta/Priming & Contexto & Imagem & Semântica \\
\hline NULL & 20 & 76 & 39 \\
A & 20 & 25 & 38 \\
C & 128 & 107 & 134 \\
I & 24 & 61 & 26 \\
N & 258 & 181 & 213 \\
\hline
\end{tabular}

Fonte: os autores. 
$\mathrm{Na}$ Tabela 3, foram plotados os mesmos dados, mas invertendose as categorias de X e da legenda. Sendo assim, pode-se fazer uma análise inversa. Para priming contextual, as respostas mais eliciadas foram $\mathrm{C}$ (correta) e $\mathrm{N}$ (neutra). Isso mostra que, efetivamente quando se tem o contexto, têm-se mais condições de compreender uma metáfora, ou ao menos compreendê-la de forma neutra. Já para o priming imagético, verifica-se que as opções NULL (ou seja, sem resposta) e I (impossível) foram mais eliciadas do que no caso dos outros estímulos. Isso nos leva a concluir que o priming imagético é o mais estrutural e concreto, e o que menos ajuda. Em tese, seria mais eficaz, mas não é. Ou seja, os resultados mostram que os fatores mais propriamente linguísticos são mais relevantes para a interpretação de metáforas. O priming imagético pode também inibir uma resposta, ou mesmo a resposta correta.

Em seguida, de acordo com o Gráfico 5, verificamos que a $\mathrm{C}$ (correta) foi eliciada principalmente pelos primings linguísticos (semântico e contextual). Inversamente à $\mathrm{C}, \mathrm{I}$ (resposta impossível) teve um maior número de respostas eliciadas pelo esquema imagético. Ou seja, apenas a representação imagética permite as mais diversas interpretações, e elas podem ser até impossíveis.

Gráfico 5 - Respostas por tipo de restrição 


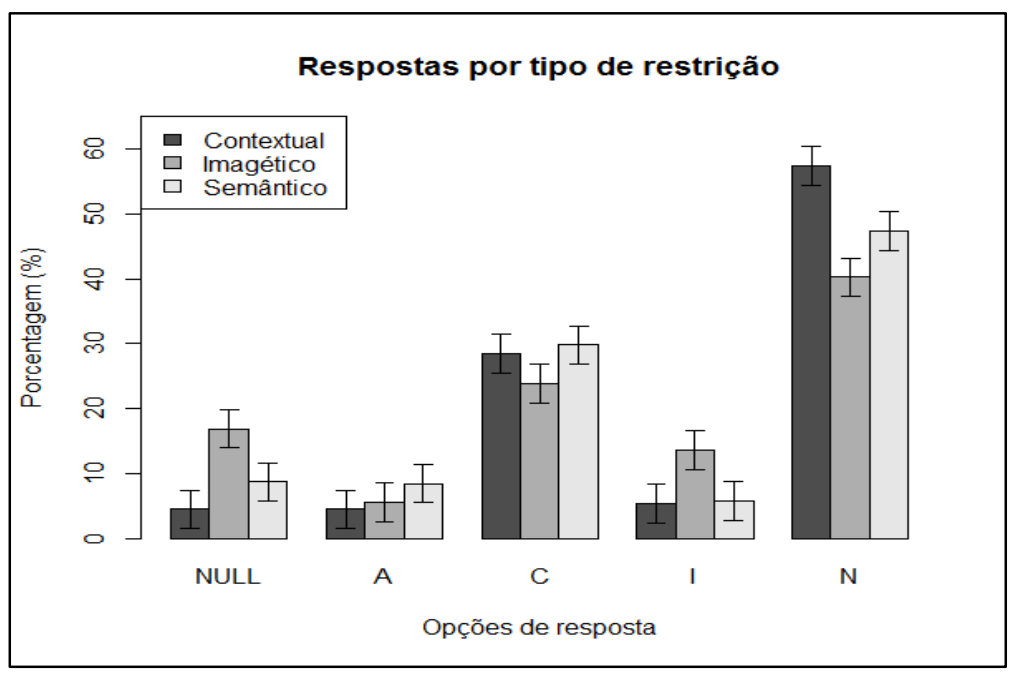

Fonte: os autores.

Isso é um dado que deve ser observado, pois mostra que a interpretação de metáforas não está ancorada, preponderantemente, em esquemas imagéticos, ao contrário do que dizem Lakoff e Johnson (1980 [2002]). Finalmente, para a resposta N, o maior número de respostas eliciadas foi para contexto. Assim, infere-se que o contexto de fato ajuda a interpretação pois favorece aquelas interpretações que são possíveis.

Finalmente, o priming semântico eliciou principalmente as opções $\mathrm{A}, \mathrm{C}$ e $\mathrm{N}$, o que leva à conclusão de que, além das respostas corretas ou neutras ativadas por esse priming, pode ser ativada uma interpretação contrária (A), pois apenas uma palavra, ainda que conectada semanticamente à metáfora, muitas vezes não basta para se chegar à interpretação correta.

Com a retirada de todas as respostas corretas e distratores dos dados, o que perfaz $57,26 \%$ do total dos dados, seguiu-se a análise de erro. Obtem-se, assim, o Gráfico 6:

Gráfico 6-Respostas erradas gerais 


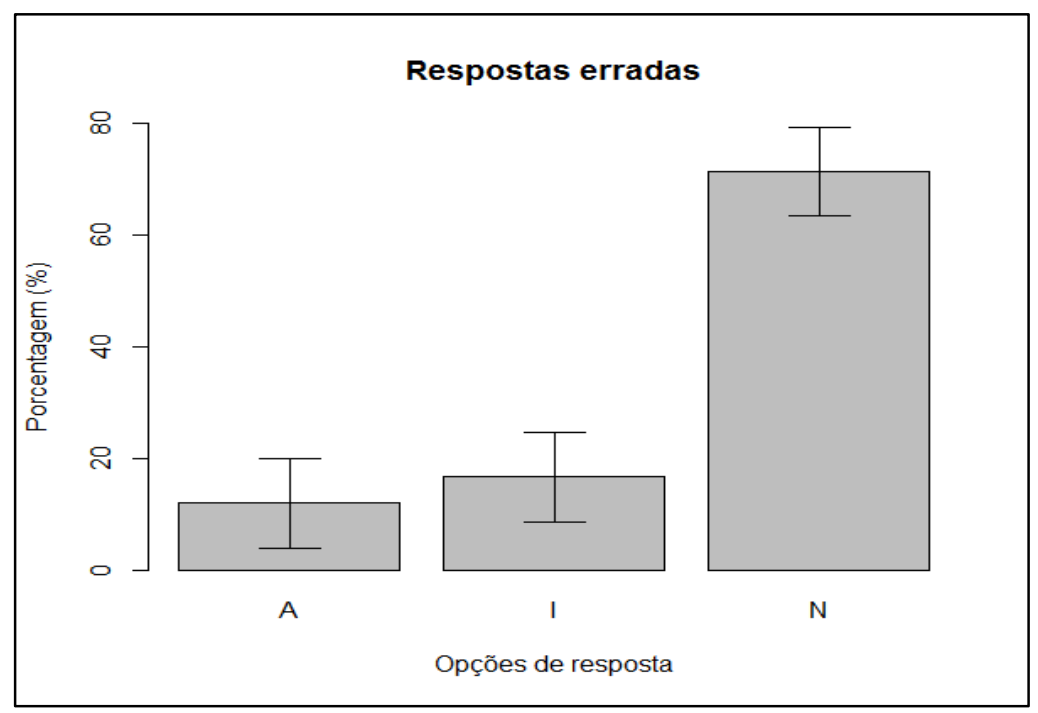

Fonte: os autores.

Observando-se o Gráfico 6, fica claro que, com a exclusão das respostas corretas, as respostas mais realizadas foram as neutras, seguidas das impossíveis e, finalmente, das respostas antônimas.

A hipótese levantada anteriormente parece ganhar um novo argumento no sentido de que, na dúvida entre uma representação metafórica fechada, os participantes preferem escolher uma resposta mais neutra. Em seguida, na Tabela 4, são apresentadas as respostas realizadas em contraste com o tipo de restrição:

Tabela 4 - Respostas por tipo de restrição

\begin{tabular}{cccc}
\hline Priming / Resposta & A & I & N \\
\hline Contexto & 13 & 23 & 162 \\
Imagem & 24 & 54 & 113 \\
Semântica & 32 & 19 & 137 \\
\hline
\end{tabular}

Fonte: os autores.

Note-se que, se contamos as $\mathrm{N}$ como corretas, ainda assim, o índice de acerto de priming imagético é inferior. Ou seja, as restrições contextuais e semânticas favorecem o acerto, tanto se considerarmos as 
respostas corretas e neutras juntas quanto se considerarmos apenas as respostas corretas.

Dessa forma, o mais razoável é aceitar que os participantes consideraram como certas não apenas o que o experimento chamou de C mas também o que o experimento chamou de $\mathrm{N}$.

Gráfico 7 - Respostas erradas por tipo de restrição

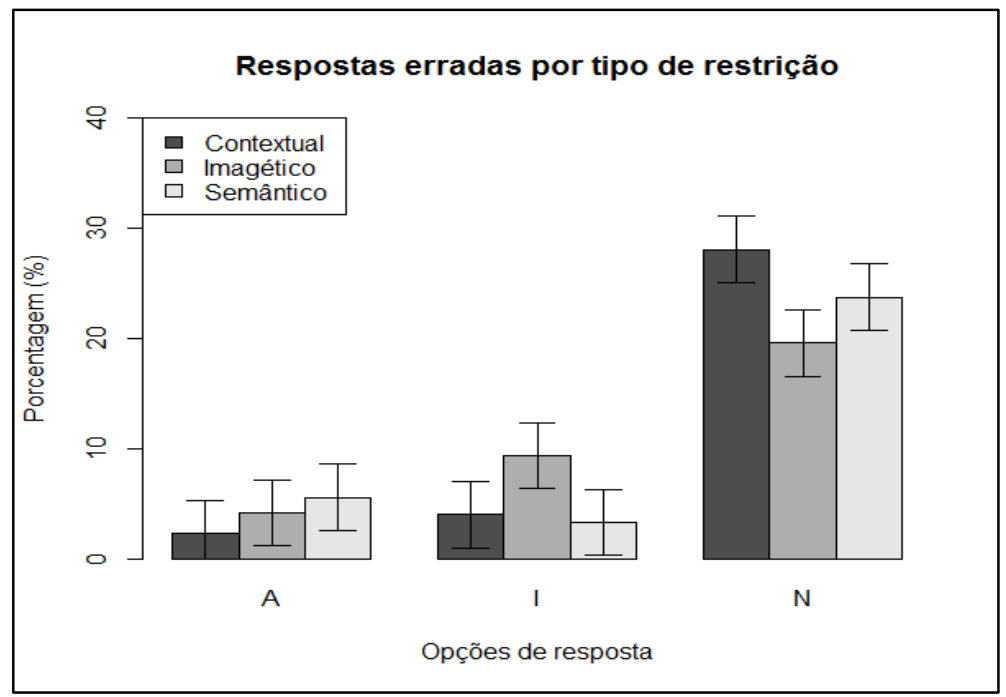

Fonte: os autores.

A análise já realizada anteriormente parece ganhar ainda mais força no sentido de que o esquema imagético é o que mais permite 
respostas impossíveis, justamente por ser uma representação mais estrutural ou esquemática, dando muito mais liberdade aos indivíduos na representação do conteúdo da metáfora.

Como se pode observar no Gráfico 7, as restrições contextuais são as que mais apresentam respostas neutras, seguidas das restrições semânticas e imagéticas. Novamente, as restrições linguísticas são as que mais contribuem para a escolha de respostas neutras.

Para se concluir os resultados e avançar para uma discussão mais geral deles, foi realizado um último teste estatístico ANOVA F1 e F2, para participantes e itens, respectivamente, em relação aos dados recémapresentados.

Em relação ao tipo de restrição, não houve um efeito significativo nem para $\mathrm{F} 1(2,396)=0,21, \mathrm{p}=0,81$, nem para $\mathrm{F} 2(2,180)=0,06, \mathrm{p}=$ 0,94 .

Já para o tipo de resposta realizada, houve uma diferença significativa, obviamente entre as respostas neutras e as demais, impossível e antônima, F1 $(2,396)=290,66$, p $<0,001$, e F2 $(2,180)=$ $82,48, \mathrm{p}<0,001$. Mais do que isso, foi encontrada uma interação significativa entre o tipo de resposta e o tipo de priming, F1(4, 396) = $12,58, \mathrm{p}<0,001$, e F2 $(4,180)=3,57, \mathrm{p}<0,01$. Entretanto, essa interação parece não interessar muito, pois trata-se da simples inversão de comportamento de resultados entre as respostas impossíveis e neutras.

Parece também que não houve um resultado significativo entre as diferentes restrições nos resultados gerais. Para se entender melhor essa falta de efeito, foram consideradas as respostas neutras e as respostas corretas e foi realizada uma análise apenas sobre as respostas neutras, para verificar se houve um efeito do tipo de restrição.

Verificou-se que o total de respostas neutras em todos os dados foi de 412 , ou seja, 30,52\% do total de dados, distribuídos da seguinte forma, por tipo de estímulo: Contextual 162 (39,32\%), Imagético 113 $(27,43 \%)$ e Semântico $137(33,25)$. Em seguida, foram verificados os resultados em relação aos tipos de restrição da resposta neutra.

Fica claro que a restrição contextual foi a que mais gerou respostas neutras, seguida da restrição semântica - as duas restrições linguísticas - e, finalmente, da restrição imagética. Assim sendo, encontramos mais um argumento para afirmar que as restrições 
contextuais foram as que mais contribuíram para a realização de respostas corretas e neutras, mas não para as respostas erradas, impossíveis e antônimas. Além disso, as restrições semânticas contribuíram mais do que as restrições imagéticas para as respostas neutras. Por fim, as restrições imagéticas parecem permitir a interpretação errada e mesmo antônima.

Em seguida, foi feita novamente uma análise de ANOVA com apenas um fator para F1 e F2, participantes e itens, respectivamente.

Os resultados da ANOVA foram significativos para $\mathrm{F} 1(2,132)=$ $13,34, p<0,001$, mas não para $\mathrm{F} 2(2,60)=1,96, \mathrm{p}=0,15$. Enfim, após serem analisados com exaustão todos os dados obtidos no experimento realizado neste trabalho, passa-se à conclusão desses resultados e às consequências para uma discussão mais geral sobre os efeitos dos tipos de restrição na interpretação de metáforas.

\section{Conclusão}

O objetivo deste trabalho foi investigar se há algum tipo de restrição (entre as restrições imagéticas, semânticas e contextuais) que favoreça mais a interpretação de metáforas. Uma das conclusões é que fatores linguísticos são relevantes para a interpretação de metáforas (MOURA, 2002, 2005, 2007, 2008, 2013a), ou seja, os falantes são sensíveis aos elementos linguísticos, sejam semânticos, sejam contextuais, aos quais uma metáfora está conectada. A pesquisa apontou ainda que a restrição contextual é a que mais influencia a interpretação da metáfora, seguida da restrição semântica.

Sendo assim, pode-se concluir que o contexto verbal no qual a metáfora está inserida contribui para a interpretação metafórica, assim como a memória semântica e as redes de relações semânticas associadas ao veículo da metáfora. Em outras palavras, a interpretação de uma metáfora depende de conexões entre signos linguísticos, ou pelo menos, da conexão de conceitos evocados por esses signos linguísticos.

A análise estatística dos dados colhidos sugere que houve prevalência da restrição contextual sobre a semântica e desta sobre a 
restrição imagética. $\mathrm{O}$ contexto linguístico ou fluxo conversacional (MOURA, 2013b) funciona como restrição principal na interpretação da metáfora.

Para a linguística cognitiva, a interpretação semântica de uma expressão linguística tem como base uma conceptualização e está ligada a todas as outras habilidades cognitivas humanas. Essa conceptualização ou processo de conceptualização são também conhecidos no campo da linguística cognitiva como construal operations (CROFT; CRUSE, 2009). Dessa forma, se a metáfora é uma operação de construal, então é natural que haja mais de uma interpretação possível para ela (corretas e neutras).

Note-se também que não foram rotuladas nenhuma das restrições como sendo de natureza cognitiva, simplesmente porque consideramos que todas as restrições analisadas (imagéticas, semânticas e contextuais) correspondem a mecanismos cognitivos. Ou seja, não foi feita a distinção, tornada clássica por Lakoff e Johnson (2002), entre o nível conceitual (cognitivo) e o nível linguístico (não cognitivo) da metáfora. Tanto a linguagem quanto os esquemas conceituais são parte de nosso aparato cognitivo.

As redes semânticas associadas às metáforas, eliciadas por signos linguísticos, funcionam como estruturas cognitivas que afetam a interpretação metafórica, da mesma forma que estruturas não verbais como os esquemas imagéticos.

Assim, as restrições linguísticas favoreceram a interpretação das metáforas mais do que os esquemas imagéticos. Com base nisso, entendemos que mecanismos cognitivos associados a estruturas linguísticas são parte intrínseca do percurso complexo por meio do qual os falantes chegam à interpretação de uma metáfora.

Outra conclusão importante é que, ao contrário da posição também clássica de Lakoff e Johnson (2002), o esquema imagético não fornece um estímulo muito preciso para a interpretação da metáfora. Os resultados deste experimento nos mostram que o esquema imagético é menos preciso e mais aberto do que as conexões verbais de que fazemos uso para a interpretação de metáforas.

Essa conclusão vai no sentido contrário à posição de muitas pesquisas no campo da linguística cognitiva, as quais apontam para a 
centralidade da representação espacial e imagética na interpretação de metáforas. Lakoff e Johnson (2002, p. 131) argumentam que os domínios espacial, social e emocional são todos elementos básicos de nossa experiência. No entanto, em termos de estruturação conceptual, o domínio espacial corresponde à base formadora dos outros domínios, em especial em usos metafóricos.

Para Langacker (2002, p. 12), a própria estrutura gramatical é imagética, pois uma construção gramatical específica produz uma imagem particular do estado de coisas a ser comunicado. Em suma, a linguagem humana se estrutura com base em esquemas imagéticos que definem e formatam o modo como conceptualizamos a realidade. Logo, nessa perspectiva, entende-se que esquemas imagéticos são uma fonte de estruturação de nossa experiência (LAKOFF, 1987, p. 110).

Tais asserções da linguística cognitiva ainda necessitam de uma comprovação no plano experimental (GIBBS, 2007). Tentamos com este experimento testá-las. A conclusão que podemos tirar não é que o esquema imagético não seja um princípio estruturador das estruturas linguísticas em geral, e das metáforas em particular. A ideia que sustentamos é que a interpretação de uma metáfora pode ser favorecida por diferentes inputs cognitivos: imagens, palavras e contextos. Os resultados obtidos, como vimos, não indicam que imagens (ou seja, input não verbal) sejam estímulos mais favorecedores da interpretação metafórica. Podemos imaginar outros experimentos em que haja uma combinação de estímulos verbais e não verbais. Gibbs (2007, p. 9) descreve experimentos em que a imagem mental é evocada por meio de perguntas, combinando, assim, o verbal e o não verbal.

A nossa posição é que não há nenhuma motivação teórica ou experimental para que imagens não verbais sejam consideradas a base da interpretação de metáforas. Entendemos que um significado pode ser evocado e eliciado por meio de elementos de natureza muito diferente, verbal e não verbal. Para entender um determinado conceito ou significado, seja literal, seja metafórico, os falantes utilizam todo o estoque possível de conhecimentos que têm daquele conceito (ECO, 2014, p. 2014). Retomando a antiga lição de Peirce (1935) de que o significado de um signo é a sua interpretação por meio de outro signo, podemos dizer que o significado de uma metáfora pode ser evocado por 
outro signo, que pode ser um diagrama, uma animação, um sinônimo ou um texto.

\section{Referências}

CROFT, W.; CRUSE, D. A. Cognitive Semantics. Cambridge: Cambridge University Press, 2009.

ECO, Umberto. Quase a mesma coisa. Experiências de tradução. Tradução de Eliana Aguiar. Rio de Janeiro: Record, 2014.

GIBBS, R. The Poetics of Mind: Figurative Thought, Language, and Understanding. New York :Cambridge University Press, 1994.

GIBBS, R. Why cognitive linguists should care more about empirical methods. In: GONZALES MARQUES, Monica; MITTELBERG, Irene; COULSON, Seana; SPIVEY, Michael (Org.). Methods in Cognitive Linguistics. Amsterdam: John Benjamins, 2007.

$<$ http://dx.doi.org/10.1075/hcp.18.06gib>

GLUCKSBERG, S. Understanding figurative language. From metaphor to idioms. Oxford: Oxford University Press, 2001.

$<$ http://dx.doi.org/10.1093/acprof:oso/9780195111095.001.0001>

GLUCKSBERG, S.; KEYSAR, B. Understanding metaphorical comparisons: beyond similarity. Psychological Review, v. 97 (1), p. 318, 1990. <http://dx.doi.org/10.1037/0033-295X.97.1.3>

KITTAY, E. F.; LEHRER, A. Semantic fields and the structure of metaphor. Studies in Language, v. 5, p. 31-63, 1981.

$<$ http://dx.doi.org/10.1075/s1.5.1.03kit>

KÖVECSES, Z. Metaphor and Emotion Language, Culture, and Body in Human Feeling. Cambridge: Cambridge University Press, 2004.

KUPFERBERG, I. Figurative positioning in media-worthy radio talk. Linguagem em (Dis)curso, vol. 7, n. 3, p. 353-370, 2007.

LANGACKER, Ronald. The cognitive basis of grammar. Berlin: Mouton de Gruyter, 2002. 
LAKOFF, G. Women, fire and dangerous things. Chicago: Chicago University Press, 1987.

$<$ http://dx.doi.org/10.7208/chicago/9780226471013.001.0001>

LAKOFF, G.; JOHNSON, M. Metaphors we live by. Chicago: Chicago University Press, 1980. Edição brasileira: Metáforas da vida cotidiana. Tradução de M. S. Zanotto e V. Maluf. São Paulo: EDUC, 2002.

LAKOFF, G.; JOHNSON, M. Philosophy in the flesh. New York: Basic Books, 1999.

LEEZENBERG, M. Contexts of Metaphor. Amsterdam, Elsevier, 2001.

MCGLONE, M. S. Conceptual metaphors and figurative language interpretation: food for thought? Journal of memory and language, v. 35, p. 544-565, 1996. <http://dx.doi.org/10.1006/jmla.1996.0029>

MOURA, H. Linguagem e cognição na interpretação de metáforas.

Veredas, v. 6, n. 1, p. 153-161, 2002.

. Metáfora: das palavras aos conceitos. Letras de hoje, v. 40 (139), p. 20-45, 2005.

- The conceptual and the linguistic factors in the use of metaphors. D.E.L.T.A., v. 22, n. especial, p. 81-94, 2006.

. Relações paradigmáticas e sintagmáticas na interpretação de metáforas. In: Linguagem em (Dis)curso, v. 7, n. 3, p. 417-452, 2007.

. Desfazendo dicotomias em torno da metáfora. Revista de Estudos da Linguagem, v. 16, n. 1, p. 179-200, 2008.

. Elementos nucleares de frame e a interpretação de metáforas. Cadernos de Estudos Linguísticos, v. 55, n.1, Campinas, Jan./Jun. 2013a.

. Significação e Contexto. 4 ed. Florianópolis: Insular, 2013b.

PEIRCE. Collected Papers. V. I-VI. Ed. Charles Hartshorne and Paul Weiss. Cambridge, MA: Harvard University Press, 1935. 
PINKER, S. Do que é feito o pensamento: a língua como janela para a natureza humana. Trad. de Fernanda Ravagnani. São Paulo: Companhia das Letras, 2008.

SCHNEIDER, W.; ESCHMAN, A.; ZUCCOLOTTO, A. E-Prime. Learning Research and Development Center. Pittsburgh: Psychology Software Tools, Inc., University of Pittsburgh, 2007. 
